Article

\title{
Numerical Analysis-Based Blast Resistance Performance Assessment of Cable-Stayed Bridge Components Subjected to Blast Loads
}

\author{
Jungwhee Lee, Keunki Choi *(D) and Chulhun Chung \\ Department of Civil \& Environmental Engineering, Dankook University, Gyeonggi-do 16890, Korea; \\ jwhee2@dankook.ac.kr (J.L.); chchung5@dankook.ac.kr (C.C.) \\ * Correspondence: ckk0204@dankook.ac.kr; Tel.: +82-31-8005-3493
}

Received: 19 October 2020; Accepted: 26 November 2020; Published: 28 November 2020

\begin{abstract}
Cable-stayed bridges are infrastructure facilities of a highly public nature; therefore, it is essential to ensure operational safety and prompt response in the event of a collapse or damage, which are caused by natural and social disasters. Among social disasters, blast accidents can occur in cable-stayed bridges as a result of explosions produced by vehicle collisions or terrorist attacks; this can lead to the degradation in their structural performances and subsequent collapse. In this research, a procedure to assess structural blast-resistance performance is suggested based on a numerical analysis approach, and the feasibility of the procedure is demonstrated by performing an example assessment. The suggested procedure includes (1) selection of major structural components that severely affect the global structural behavior, (2) set-up blast hazard scenarios consisting of various blast levels and locations, and (3) assessment of the components using numerical blast simulation. By performing an example assessment, the critical blast level for each component could be determined and the blast location that affects the considering components the most severely could be found as well. The scenario-based assessment process employed in this study is expected to facilitate the evaluation of bridge structures under blasts in both existing bridges and future designs.
\end{abstract}

Keywords: cable-stayed bridge; social disaster; blast scenario; blast analysis; LS-DYNA

\section{Introduction}

Various important infrastructure facilities are currently under construction, both domestically and internationally. The 9/11 terrorist attacks in the United States aroused social awareness of the safety of important infrastructure facilities such as cable-stayed bridges. Furthermore, the preparedness of infrastructure facilities against disasters has emerged as a major issue, and the need for an engineering review of the safety of infrastructure facilities has been recognized; at present, many countries are making continuous budget investments in maintenance and related fields to prepare for such disasters. In particular, disaster-induced accidents on long-span bridges (e.g., cable-stayed bridges) can result in enormous losses of life and significant damage to the economy, because these infrastructure facilities are of a highly public nature. Disasters can be classified into natural disasters (e.g., earthquakes, typhoons, and floods) and social disasters caused by accidents (e.g., fire, collisions, explosions) and terrorist activities. Among the latter category, blast accidents in cable-stayed bridges can occur as a result of explosions caused by vehicle collisions and terrorist attacks; these can lead to significant deterioration in their structural performance, which may cause the bridge to collapse.

Over the last seven decades, more than six hundred terrorist attacks on bridges and other infrastructure facilities have been recorded [1]. In addition, the Seohae Bridge in South Korea was exposed to a blast risk from a large vehicle accident in 2006. In 2007, the Al-Sarafiya Bridge in Bagdad, 
Iraq, collapsed due to an attack by a suicide bomber. Furthermore, vehicle blast accidents have occurred on the Riyadh Bridge, Saudi Arabia (2012) and the Sanmenxia Bridge, China (2013). Despite these bridge accidents, no criteria or method has been established to evaluate entire bridge structures prior to construction. Several studies have conducted full-scale experiments to evaluate the performances of piers and decks (structural components of general road bridges) in the event of blasts [2-7]. Based on previous experiments, Williamson et al. [8] suggested three blast design categories, and Williams and Williamson [9] developed a numerical model to describe the spalling of concrete piers using the simulation software package LS-DYNA. Furthermore, several studies have conducted blast analyses for general road bridges using 2D and 3D models [10-13]. However, previous studies had limited capacity to directly or indirectly evaluate the overall performance of cable-stayed bridges subjected to blasts; thus, many researchers have recently begun to numerically simulate blasts in such bridges. Deng and Jin [14] examined stress distributions in a bridge using a 3D cable-stayed bridge model in the simulation software ANSYS AUTODYN; they used a blast pressure derived from 1D analysis, without distinct blast scenario settings. Tang and Hao $[15,16]$ verified the response of a cable-stayed bridge to displacement and stress by numerically analyzing the case of a truck blast occurring $0.5 \mathrm{~m}$ from the pier and $1.0 \mathrm{~m}$ above the deck. Son and Lee [17] conducted fluid-structure interaction analyses for two types of pylons (hollow steel box and concrete-filled composite pylons) by applying a compressive force to the pylon top. Bojanowski and Balcerzak [18] introduced the procedure and results of a numerical analysis method for evaluating the performance of a complete cable-stayed bridge system under a blast load, and they specified and applied the blast load cases of cars and trucks. Hashemi et al. [19,20] conducted blast analysis for steel cable-stayed bridges, by setting bridge blast scenarios with three load levels (small, medium, and large) and examining the damage and responses of components. Pan et al. [21] defined several scenarios of human-installed explosives and blast accidents caused by trucks, and they analyzed blast load responses for a slab-on-girder, box-girder, and long-span cable-stayed bridges. Farahmand-Tabar et al. [22] evaluated the risks of a progressive collapse and performance degradation in suspension bridges by using a 2D suspension bridge model.

To evaluate the performance of cable-stayed bridges under different blast loads, the aforementioned studies analyzed the overall behaviors and damage characteristics of bridges by modeling either the deck and pylon only or the entire structure [14-22]. Furthermore, when setting the blast loads, they often chose randomized blast loads, rather than setting them according to specific scenarios [14-17,22]. Most of the existing studies have focused on the behaviors of entire bridges, and very few cases have analyzed the damage types or levels of major components (e.g., the cables) according to different scenarios. Therefore, this study conducts blast analysis by defining a detailed finite element model for the major components of the target bridges and setting appropriate blast scenarios, as shown in the procedure in Figure 1. Furthermore, the effects of the blast load are examined by analyzing the component responses and damage types.

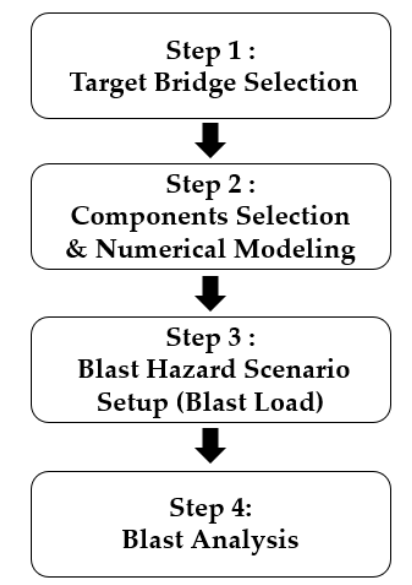

Figure 1. Blast analysis process. 


\section{Target Structure and Numerical Modeling}

\subsection{Target Structure}

To analyze the performances of the major components of a cable-stayed bridge under a blast load, we selected the target bridge as shown in Figure 2; it is a cable-stayed bridge featuring three spans, with a main span length of $470 \mathrm{~m}$ and a side span length of $200 \mathrm{~m}$. It is a composite superstructure formed of precast reinforced concrete (RC) slabs and steel girders (edge girder, center stringer, and crossbeam). The deck is $310 \mathrm{~mm}$ thick near the pylon and $260 \mathrm{~mm}$ thick in other sections, and it is made of 68 standard segments (length $(\mathrm{L})=12.3 \mathrm{~m}$ ). In addition, the bridge features 144 cables of varying areas and lengths and two RC pylons (PY1 and PY2), which contain hollow sections. To evaluate each component of the cable-stayed bridge, a single 260-mm thick segment at the center of the span was selected from the superstructure. We selected the following cables for analysis: Cable no. 37 (area (A) = $0.012450 \mathrm{~m}^{2}, \mathrm{~L}=252 \mathrm{~m}$ ), which is the longest cable, has the largest cross-sectional area, and extends to the mid-point of the superstructure; Cable no. $53\left(\mathrm{~A}=0.005185 \mathrm{~m}^{2}, \mathrm{~L}=81 \mathrm{~m}\right)$, which has the smallest cross-sectional area; and Cable no. $68\left(\mathrm{~A}=0.009385 \mathrm{~m}^{2}, \mathrm{~L}=206 \mathrm{~m}\right)$, which is attached to the side span, where the largest stress is applied. We selected PY2 as the pylon; its base segment (CB1 in the figure) is $2.37 \mathrm{~m}$ taller than that of PY1.

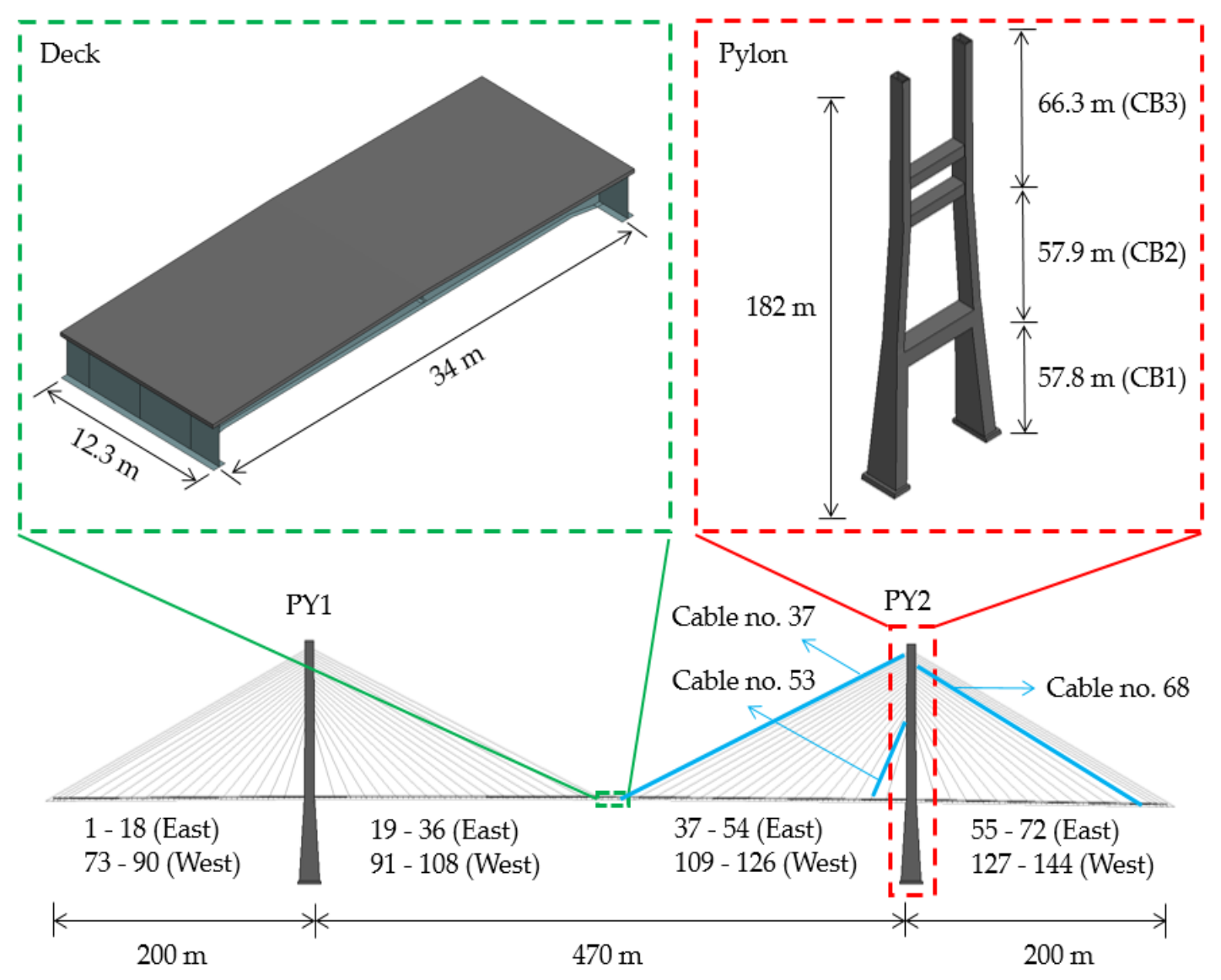

Figure 2. Target bridge components.

Tables 1 and 2 summarize the specifications of the steel girders and rebars comprising each component; these values were taken from [23]. 
Table 1. Steel girder details.

\begin{tabular}{ccc}
\hline \multicolumn{2}{c}{ Part } & Thickness (mm) \\
\hline \multirow{3}{*}{ Edge Girder } & Upper flange & 50 \\
& Lower flange & 50 \\
& Web & 22 \\
\hline \multirow{3}{*}{ Center Stringer } & Upper flange & 30 \\
& Lower flange & 20 \\
& Web & 12 \\
\hline \multirow{3}{*}{ Crossbeam } & Upper flange & 30 \\
& Lower flange & 30 \\
& Web & 14 \\
\hline
\end{tabular}

Table 2. Rebar details.

\begin{tabular}{ccc}
\hline Part & $\begin{array}{c}\text { Vertical Rebar } \\
\text { Diameter and Spacing }(\mathbf{m m})\end{array}$ & $\begin{array}{c}\text { Lateral Rebar } \\
\text { Diameter and Spacing }(\mathbf{m m})\end{array}$ \\
\hline Deck & H19@150 & H16@150 \\
Pylon (CB1) & H35@125 & H22@100, H19@250 \\
Pylon (CB2, CB3) & H29@125 & H22@100 \\
\hline
\end{tabular}

\subsection{Finite Element Model Development}

Finite element modeling was performed using the general-purpose finite element program LS-DYNA [24]. For the deck model, 8-node solid elements, 4-node shell elements, and 2-node beam elements are used for the concrete slab, steel girder, and reinforcing bars, respectively. The deck model consists of 288,332 nodes and 198,550 elements, and the edge lengths range from 0.05 to $0.15 \mathrm{~m}$. The concrete slab of the model is divided into 5 layers of elements. Stay cables are modeled as solid round bar shapes with 8-node solid elements. The numerical models of the cable \#37, 53, and 68 consist of $87,362,39,668,73,205$ nodes and 77,686, 35,316, 65,232 elements, respectively. The overall edge length ranges from 0.10 to $0.50 \mathrm{~m}$, and the finer mesh with 0.02 to $0.05 \mathrm{~m}$ of edge length is generated at the region of the application of the blast load. In the pylon model, there is a concrete part and a reinforcing bar part. The concrete part and the reinforcing bar parts consist of 8-node solid elements and 2-node beam elements, respectively, and the pylon model has 1,185,084 nodes and 917,438 elements. The section submitted to the blast load was modeled with smaller element sizes of 0.05 to $0.20 \mathrm{~m}$. The remaining sections were configured using element sizes of approximately $0.5 \mathrm{~m}$. For the rebars, the specifications in Table 2 were applied. The composite conditions for the concrete and rebars were implemented using the *CONSTRAINED_LAGRANGE_IN_SOLID command. The contact condition between the steel girders was applied considering the case of a large, load-induced deformation, using the *AUTOMATIC_SINGLE_SURFACE command. Figures 3-5 illustrate the finite element models of the superstructure, cables, and pylon.

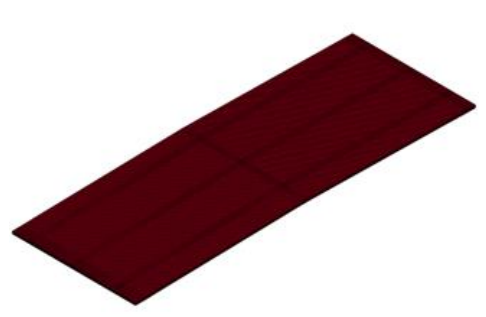

(a)

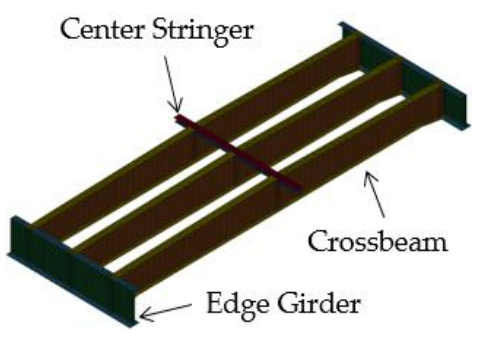

(b)

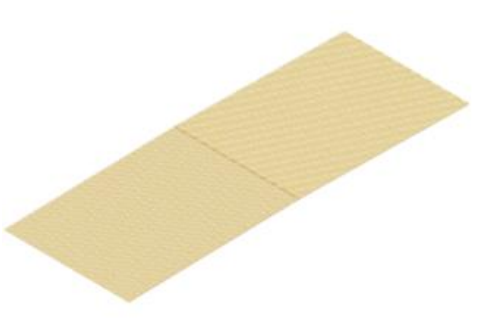

(c)

Figure 3. Deck model: (a) slab, (b) steel girder, and (c) rebar. 


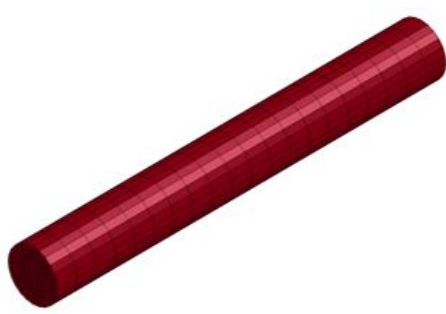

(a)

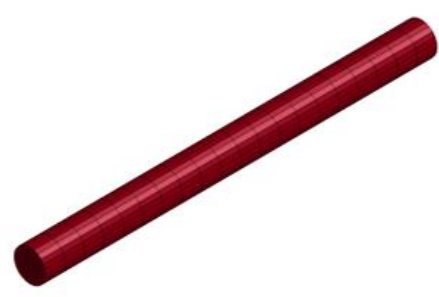

(b)

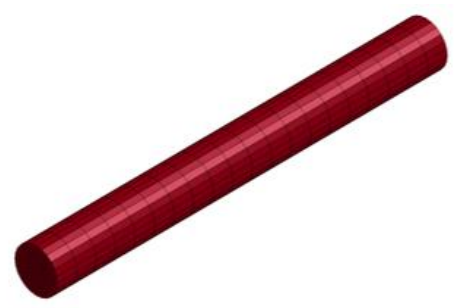

(c)

Figure 4. Cable model: (a) Cable no. 37, (b) Cable no. 53, and (c) Cable no. 68.

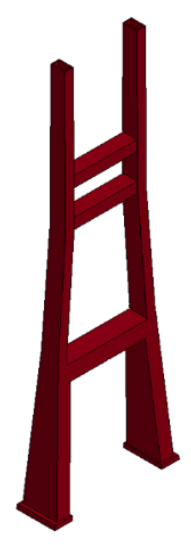

(a)

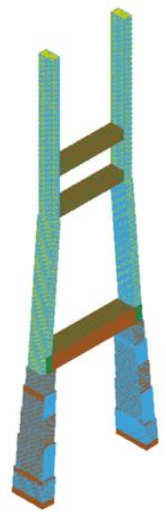

(b)

Figure 5. Pylon model: (a) concrete part and (b) rebar.

\subsection{Material Model}

When selecting a material model for blast analysis, various material properties-in particular, the strength increasing effect due to the strain rate-must be considered. Therefore, we selected the following material model from LS-DYNA:

For the concrete, the *MAT_CSCM_CONCRETE material model was applied; this captures the nonlinear material behaviors of concrete, as well as its stiffness degradation arising from damage, erosion, and the strain rate effect $[25,26]$. A compressive strength $\left(\mathrm{f}_{\mathrm{ck}}\right)$ of concrete was selected as $39.23 \mathrm{MPa}$, and 1.05 was used as the ERODE parameter, to simulate erosion of the concrete element in the blast analysis.

To model the steel plates in the girders, rebars, and cables, the *MAT_PLASTIC_KINEMATIC material model was applied. This model considers the strain rate effect, isotropy, and kinematic hardening of the material, and it assumes a bi-linear material nonlinearity. The material constants $\mathrm{C}$ and $p$ (used in the Cowper-Symonds model, which describes the strain rate effect) were determined using the following equation, developed for high-strength steel [27]. Usually, the $C$ value of 40 is applied to normal structural steel, but this value is known to overestimate the strain rate effect of high-strength steel. Therefore, the experimentally validated Equation (1) is used to calculate the $C$ value in order to prevent overestimation of the strain rate effect.

$$
C=\left\{\begin{array}{c}
92000 \cdot \exp \left(\frac{\sigma_{0}}{364}\right)-194000, \sigma_{0}>270 \mathrm{MPa}, \\
40, \sigma_{0} \leq 270 \mathrm{MPa},
\end{array}\right.
$$

where, $\sigma_{0}$ is the yield stress (MPa). In addition, the strengths selected for the steel plates in the girders were varied according to the thickness. The input parameters used for each material model are listed in Table 3. 
Table 3. Material model input parameters.

\begin{tabular}{ccc}
\hline Part & Category & Input Parameter \\
\hline \multirow{2}{*}{ Concrete } & Deck, Pylon & $\mathrm{f}_{\mathrm{ck}}=39.23 \mathrm{MPa}, \mathrm{E}=33.107 \mathrm{GPa}$, \\
& $\rho=2,300 \mathrm{~kg} / \mathrm{m}^{3}$, ERODE $=1.05$
\end{tabular}

\subsection{Initial Load and Boundary Conditions}

To assess the structural performance of each major bridge component such as pylon, deck, and cables, initial compressive forces and tensile forces of the components should be considered. During the application of tension to the stay cables, compressive forces result in the pylon and deck while tensile forces are generated in the cables as shown in Figure 6a. The distribution of compressive forces along the bridge's length is depicted in Figure $6 \mathrm{~b}$. Since the compressive forces which are transferred from each stay cable are accumulated, compression of the deck section gradually increases as it approaches the pylon. In another point of view, a very small amount of compression results on the deck section of the center of the mid-span. The deck segment of the current numerical analysis is located at the center of the mid-span, and the design compression of the section is approximately $1.8 \%$ of the maximum compression of the deck, according to the design documents $[23,28]$. Therefore, the compressive force of the considered segment is regarded as negligible, and only the self-weight of the segment is considered as the initial load.

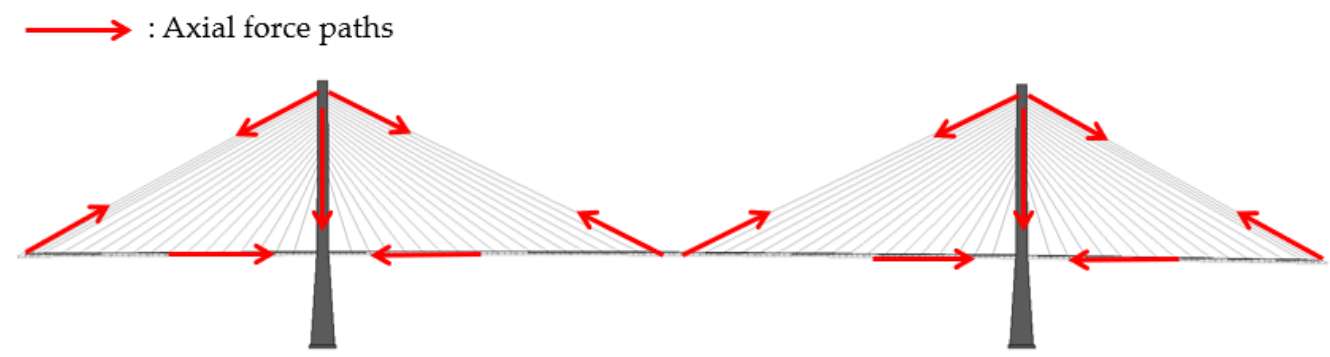

(a)

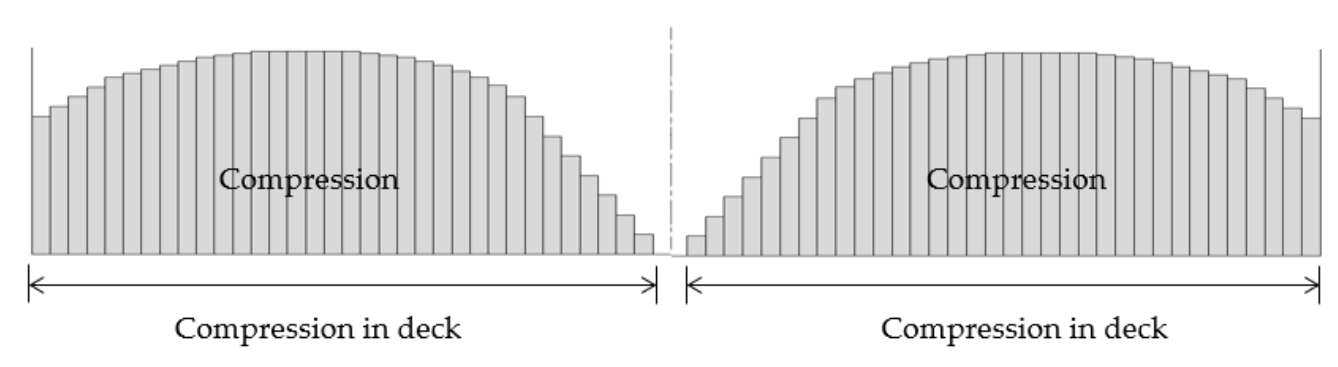

(b)

Figure 6. Axial force in cable-stayed bridge: (a) axial force paths and (b) axial force in deck. 
Initial loads and boundary conditions of each numerical model of the bridge components are shown in Figure 7. As previously mentioned, only self-weight is considered as the initial load for the deck model. As a boundary condition of the deck model, the longitudinal symmetry condition is considered, and the z-directional translation is constrained at the location of cable anchorage.

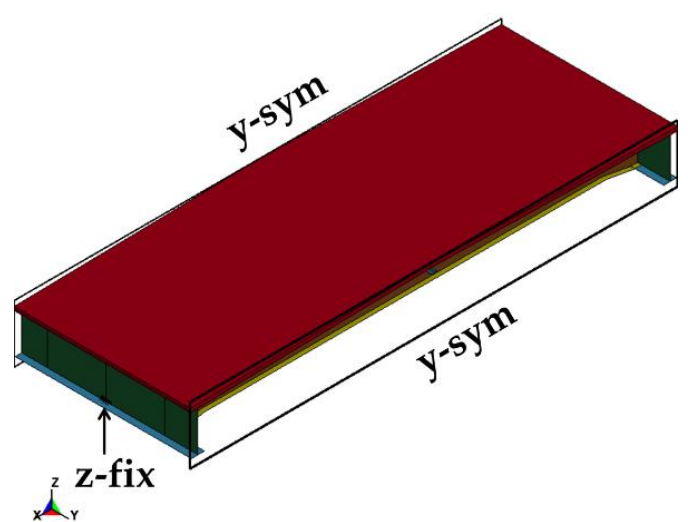

(a)

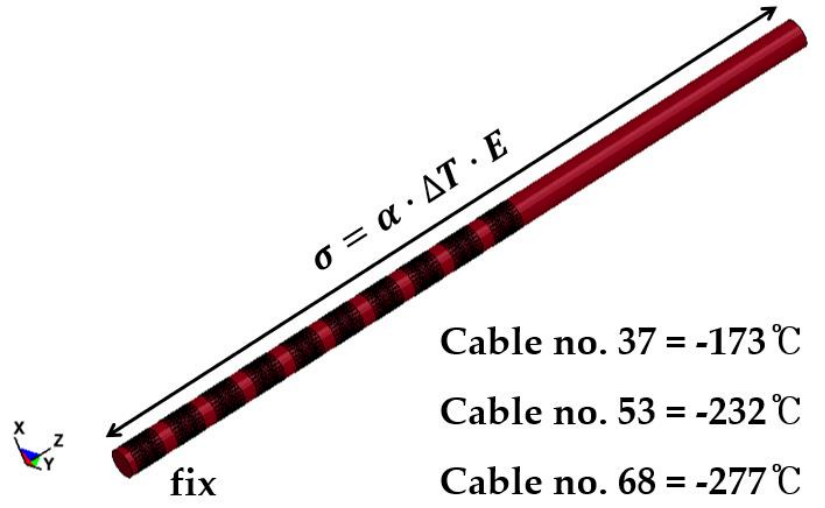

(b)

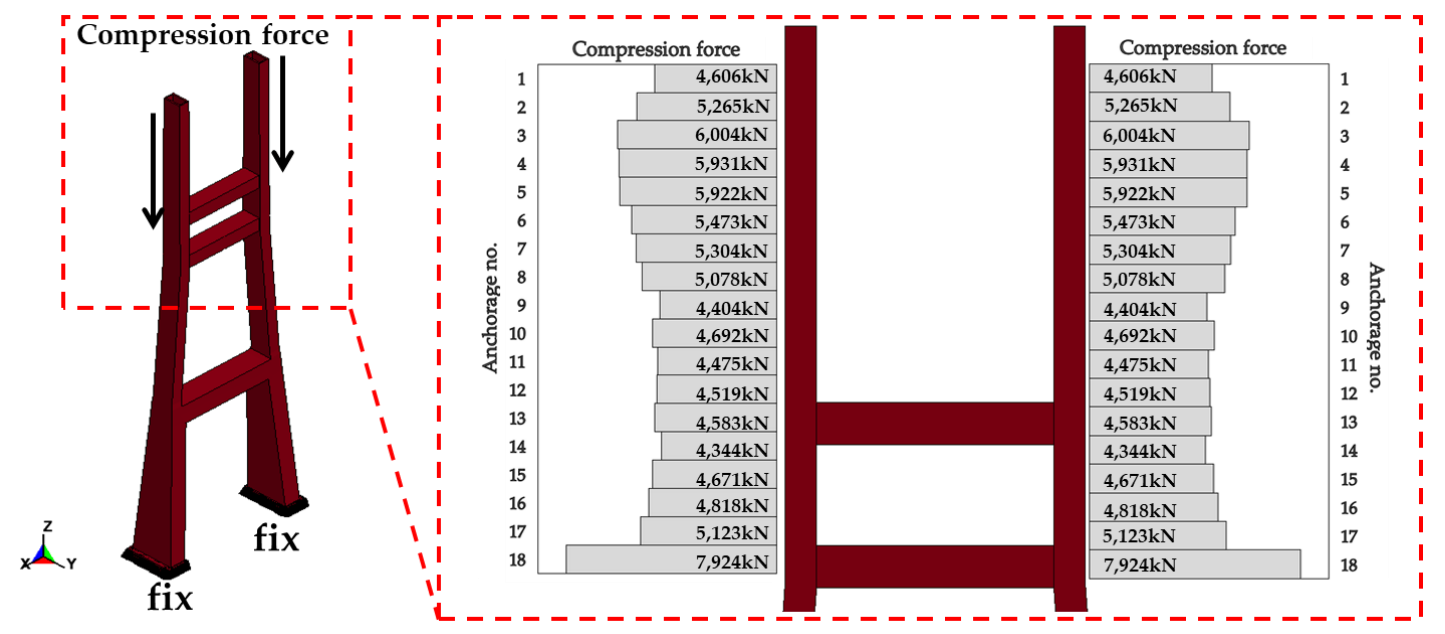

(c)

Figure 7. Initial load and boundary conditions: (a) deck, (b) cable, and (c) pylon.

For the cable models, translational DOFs of surface nodes at each end region are constrained considering the anchored length. Thermal load is utilized to apply the initial stresses of each cable model of nos. 37, 53, and 68, which are 415, 556, and $665 \mathrm{MPa}$, respectively. For thermal load analysis, the temperature change is calculated using the thermal stress Equation (2) with the general thermal expansion coefficient of steel, $1.2 \times 10^{-5} /{ }^{\circ} \mathrm{C}$. The calculated temperature drops are $-173,-232$, and $-277^{\circ} \mathrm{C}$ for Cable nos. 37,53 , and 68 , respectively.

$$
\sigma=\alpha \cdot \Delta T \cdot E
$$

where, $\sigma_{T}$ is thermal stress (MPa), $\alpha$ is coefficient of thermal expansion $\left(/{ }^{\circ} \mathrm{C}\right), \Delta T$ is temperature change $\left({ }^{\circ} \mathrm{C}\right)$, and $E$ is elastic modulus (MPa). The LS-DYNA commands, ${ }^{*}$ LOAD_THERMAL_VARIABLE and *MAT_ADD_THERMAL_EXPANSION, are used for thermal analysis.

For the pylon model, a fixed boundary condition is applied on the bottom surface of each pylon leg. Also, the compressive forces transferred from the stay cables are applied on the nodes at cable anchorages as initial loads. The amounts of compressive forces are shown in Figure $7 \mathrm{c}$, and the 
total compression is approximately $186,000 \mathrm{kN}$. Self-weight is also considered as initial load, and the LS-DYNA command, *CONTROL_DYNAMIC_RELAXATION, is used for initial load analysis.

\section{Blast Scenario and Load Cases}

\subsection{Blast Scenario}

Selecting an appropriate scenario from among the various possible blast events and setting the size of the blast load are essential to the performance evaluation and risk analysis. Blasts that occur on bridges are unpredictable and - on both domestic and overseas bridges-have been caused by explosions from terrorist attacks, vehicle accidents, and other events (e.g., wars). When conducting blast analysis for bridges, most previous researchers have used random blast loads, rather than setting separate blast or vehicle explosion scenarios [14-17,22]. This study defined blast accident scenarios in terms of vehicle-based terrorist attacks, considering the current likelihood of war-related blast accidents to be low. A virtual scenario describing a terrorist attack conducted through explosive-laden vehicles was assumed. Thus, the quantity of explosive (TNT) and height of the explosion above the road were set according to the maximum load and ground clearance of general-purpose vehicles driven in South Korea. A TNT load of 1000-1500 kg was considered, which is classified as a very large load considering the explosive definitions introduced in [29] or the quantities of explosive used in the American Society of Mechanical Engineers-American Concrete Institute explosion tests [30]. Table 4 presents the blast scenario specifications employed in this study.

Table 4. Blast scenarios.

\begin{tabular}{ccccc}
\hline Blast Scenario. & Vehicle Type & $\begin{array}{c}\text { Ground Clearance } \\
(\mathbf{m m})\end{array}$ & $\begin{array}{c}\text { Maximum Load } \\
\mathbf{( k g )}\end{array}$ & $\begin{array}{c}\text { TNT Load } \\
\mathbf{( k g )}\end{array}$ \\
\hline Scenario A & Passenger car & 700 & 226.8 & 226.8 \\
Scenario B & Truck & 800 & 1500 & 500 \\
Scenario C & Truck & 800 & 1500 & 1000 \\
Scenario D & Truck & 800 & 1500 & 1500 \\
\hline
\end{tabular}

\subsection{Blast Load Cases}

The blast load cases defined in this study are illustrated in Figure 8; they were set by considering the positions of the target components and lanes. For the superstructure case, it was assumed that the vehicle explodes in the second lane, either between crossbeams or immediately above one. For the pylon and cable case, explosions were assumed to occur on the shoulder, where the vehicle is closest to the target component. In blast load modeling, the load was applied after calculating the explosion pressure using the scaled distance, which was calculated from the TNT quantity and the distance from the explosion location to the target structure. This method allows the load of CONWEP to be applied indirectly using the *LOAD_BLAST_ENHANCED and *LOAD_SEGMENT_SET commands provided in LS-DYNA. Therefore, we applied the blast load using these commands. Because the blast load is reflected from the deck at the moment of detonation, the shock wave was assumed to propagate hemispherically. Table 5 summarizes the blast load cases in terms of the target components and scaled distances.

Table 5. Blast load cases.

\begin{tabular}{cccc}
\hline Blast Scenario & Component & $\begin{array}{c}\text { TNT } \\
(\mathbf{k g})\end{array}$ & $\begin{array}{c}\mathbf{Z} \\
\text { (Scaled Distance, } \mathbf{~} / \mathbf{k g} \mathbf{k}^{\mathbf{1 / 3}} \text { ) }\end{array}$ \\
\hline Scenario A & & 226.8 & 0.115 \\
Scenario B & Deck & 500 & 0.101 \\
Scenario C & 1000 & 0.080 \\
Scenario D & & 1500 & 0.070 \\
\hline
\end{tabular}


Table 5. Cont.

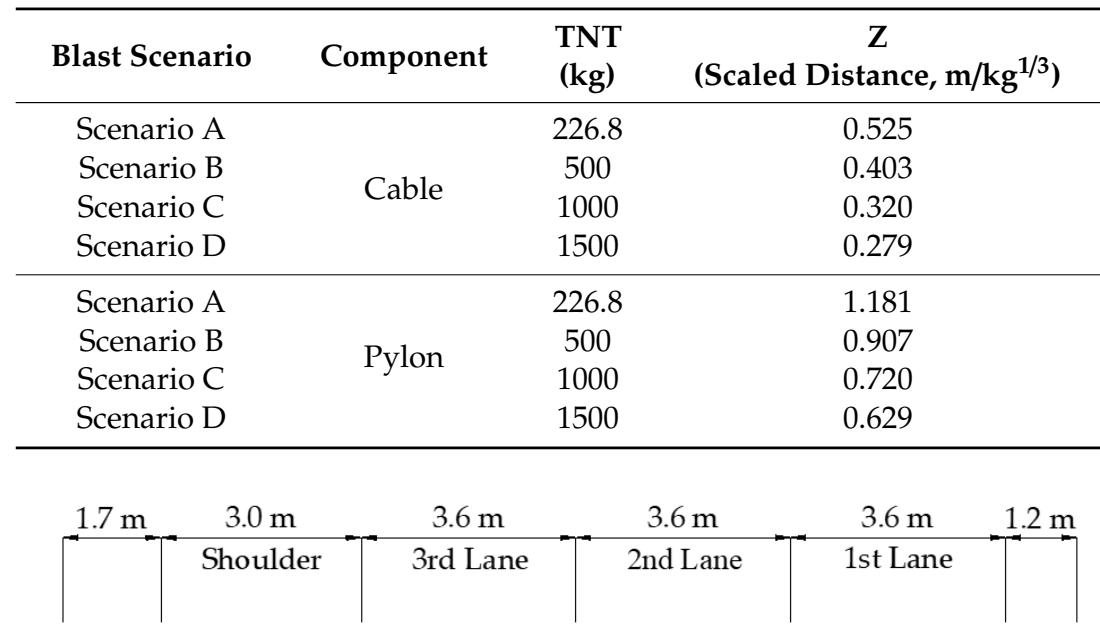

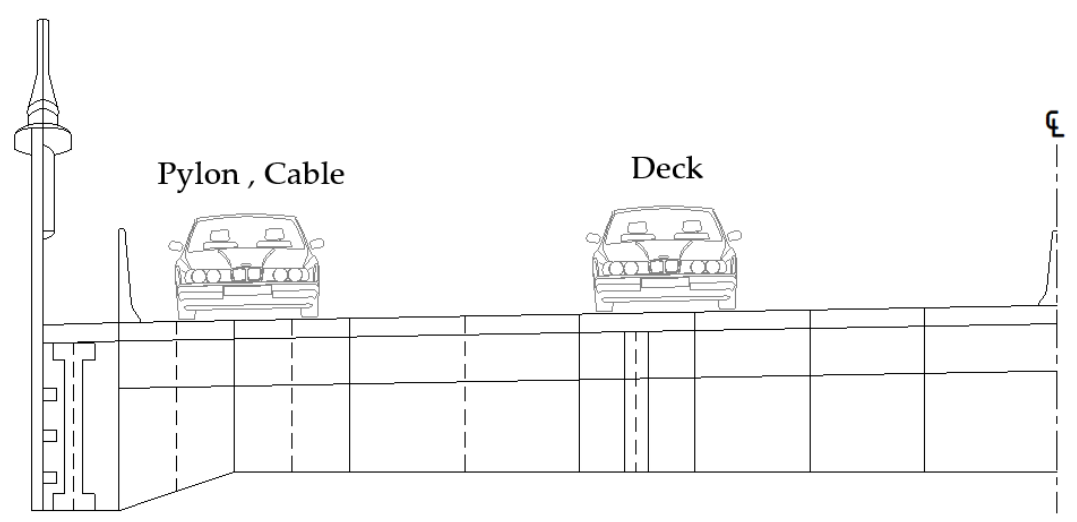

(a)

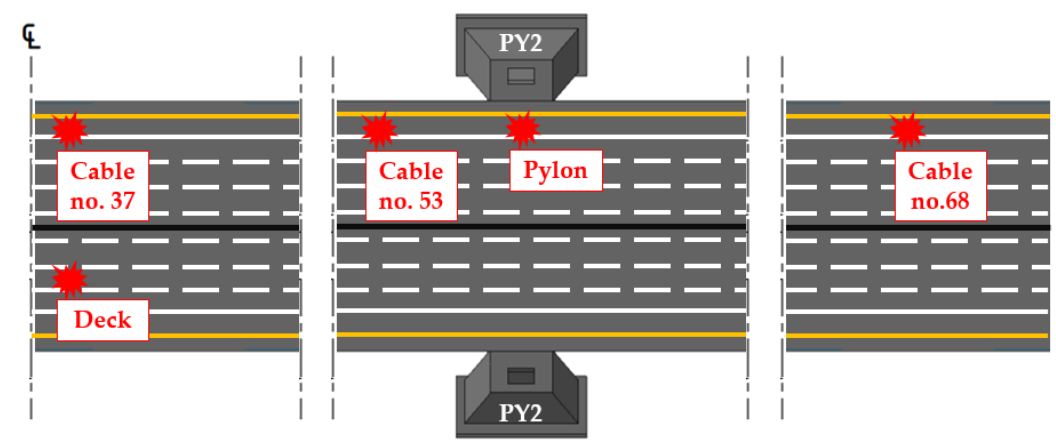

(b)

Figure 8. Blast load position: (a) cross-sectional view and (b) plan view.

\section{Blast Analysis Results}

Numerical blast simulations were performed to evaluate the explosion resistance performances of major components of the cable-stayed bridge. The stress, displacements, and damage levels of the components were examined. The numerical analysis results show that the response sizes and damage ranges of all components increase with the blast load. The blast analysis results of the major components are described below for different scenarios. In addition, Table 6 summarizes the time step and CPU time utilized for the analysis of each numerical model. The numerical analysis of this study was all performed with a single CPU. 
Table 6. Summary of utilized time step size and CPU time.

\begin{tabular}{cccc}
\hline Model & Number of Elements & $\begin{array}{c}\text { Time Step Size } \\
\left(\mathbf{1 0}^{-\mathbf{6}} \mathbf{s}\right)\end{array}$ & $\begin{array}{c}\text { CPU Time } \\
\text { (s) }\end{array}$ \\
\hline Deck & 198,550 & $4.826-4.943$ & $49,670-50,568$ \\
Cable no. 37 & 77,868 & $0.861-0.868$ & $54,115-56,275$ \\
Cable no. 53 & 35,316 & $0.545-0.554$ & $37,015-40,345$ \\
Cable no. 68 & 65,232 & $0.735-0.745$ & $52,948-54,090$ \\
Pylon & 917,438 & $7.257-11.092$ & $87,009-95,547$ \\
\hline
\end{tabular}

\subsection{Deck}

Table 7 summarizes the damage types and maximum stresses of the steel girder in each scenario, for a blast load applied between and above the crossbeams of the superstructure. The slab's displacement and response to rebar stress were not examined, because the analysis results included the occurrence of perforation. In blast analysis between the superstructure crossbeams, the damage range of the slab was found to increase with the blast load; however, the main damage occurred only between the crossbeams. In the damage assessments for each scenario, scabbing of the slab was observed in Scenario A, and slab perforations were observed in Scenarios B-D. When the effective stress and degree of damage of the steel girder were examined, the effective stress was found to increase with the blast load. Furthermore, the maximum stresses in Scenarios A-D were 434, 452, 479, and $509 \mathrm{MPa}$, respectively, and deformation occurred in the upper flange of the crossbeam. The ultimate strength $\left(f_{u}\right)$ of the steel girder was $520 \mathrm{MPa}$; hence, it was concluded that the steel girder plastically deforms but does not fracture when a blast load is applied between the crossbeams of the superstructure.

Table 7. Summary of blast analysis results of the deck.

\begin{tabular}{|c|c|c|c|c|}
\hline \multirow{2}{*}{ Blast Scenario } & \multirow{2}{*}{ Blast Position } & \multirow{2}{*}{$\begin{array}{l}\text { Damage Type of } \\
\text { Slab }\end{array}$} & \multicolumn{2}{|c|}{ Steel Girder } \\
\hline & & & Maximum Stress & Damage Type \\
\hline Scenario A & \multirow{4}{*}{$\begin{array}{l}\text { 2nd lane/ } \\
\text { Between } \\
\text { crossbeams }\end{array}$} & Scabbing & $434 \mathrm{MPa}$ & \multirow{4}{*}{ Plastic deformation } \\
\hline Scenario B & & \multirow{3}{*}{ Perforation } & $452 \mathrm{MPa}$ & \\
\hline Scenario C & & & $479 \mathrm{MPa}$ & \\
\hline Scenario D & & & $509 \mathrm{MPa}$ & \\
\hline Scenario A & \multirow{4}{*}{$\begin{array}{c}\text { 2nd lane/ } \\
\text { Above crossbeam }\end{array}$} & Scabbing & $602 \mathrm{MPa}$ & Plastic deformation \\
\hline Scenario B & & \multirow{3}{*}{ Perforation } & - & \multirow{3}{*}{ Ruptured } \\
\hline Scenario C & & & - & \\
\hline Scenario D & & & - & \\
\hline
\end{tabular}

In the analysis of a blast above the superstructure crossbeam, the damage range of the slab was found to increase with the blast load and was wider than that seen for the blast between the crossbeams. The damage types of each scenario were identical to those of the previous case. When the effective stress of the steel girder was examined, a stress of $602 \mathrm{MPa}$ (exceeding the ultimate strength $\left(f_{\mathrm{u}}\right)$ of the steel girder (520 MPa)) occurred momentarily in the upper flange and web of the crossbeam in Scenario A; however, it appears that no damage occurred owing to the strain rate effect of the material. In Scenarios B-D, the crossbeam was damaged, and the damage range increased with the blast load. This suggests that in the case of the superstructure, a blast load applied to the crossbeam causes greater damage (and has a larger effect on the structural behavior of the cable-stayed bridge) than the blast load applied between the crossbeams.

Figures 9-12 show the damage and effective stress contours generated by the blast load. The fringe range of the effective stress contour was set to $0-520 \mathrm{MPa}$, considering the ultimate strength of the steel girder; the resulting output time was $0.05 \mathrm{~s}$, at which point the analysis was terminated. 


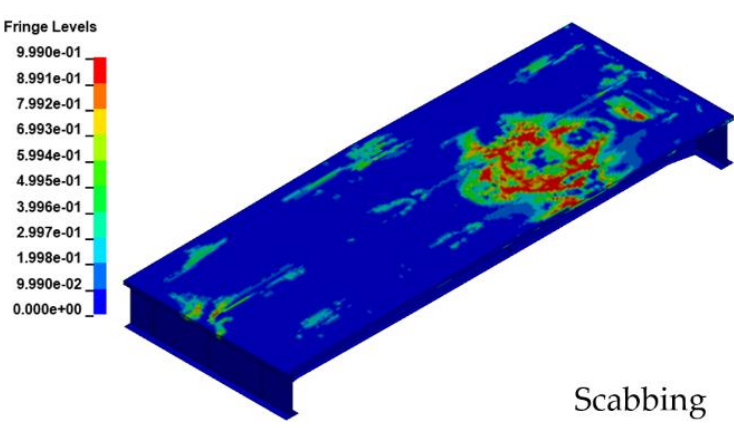

(a)

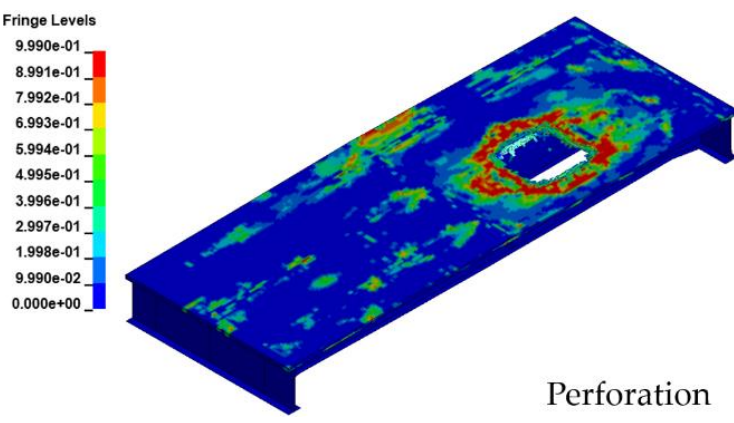

(c)

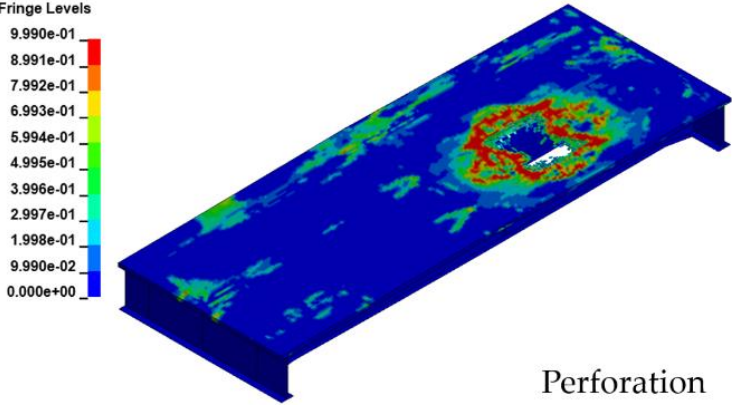

(b)

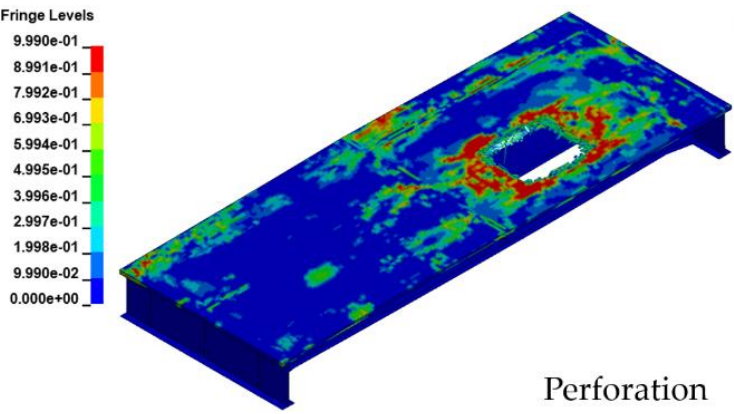

(d)

Figure 9. Damage contours of the deck (between the crossbeams): (a) Scenario A, (b) Scenario B, (c) Scenario C, and (d) Scenario D.

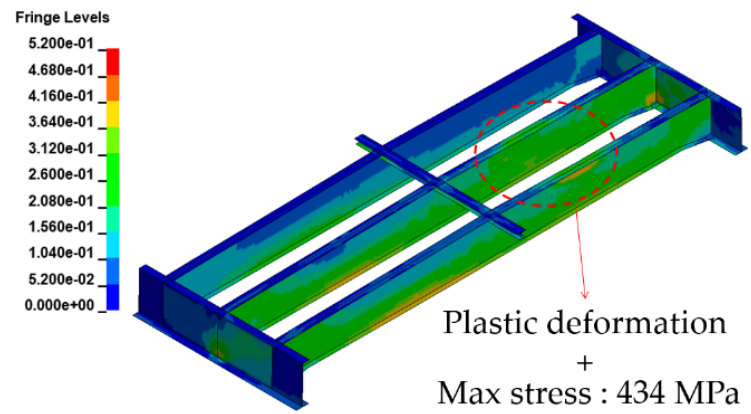

(a)

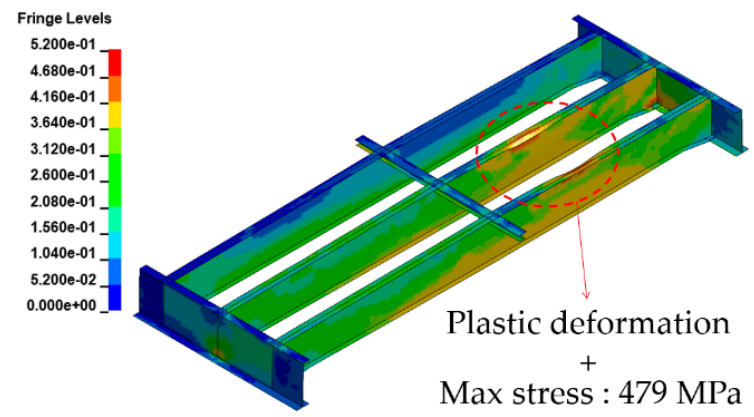

(c)

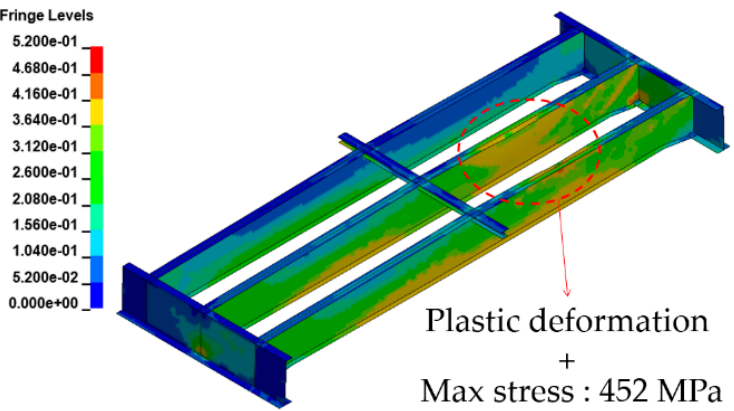

(b)

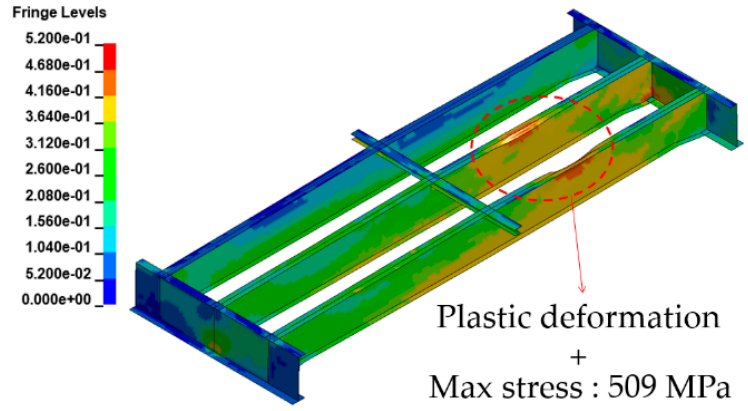

(d)

Figure 10. Effective stress contours of the steel girder (between the crossbeams): (a) Scenario A, (b) Scenario B, (c) Scenario C, and (d) Scenario D (fringe level unit: MPa). 


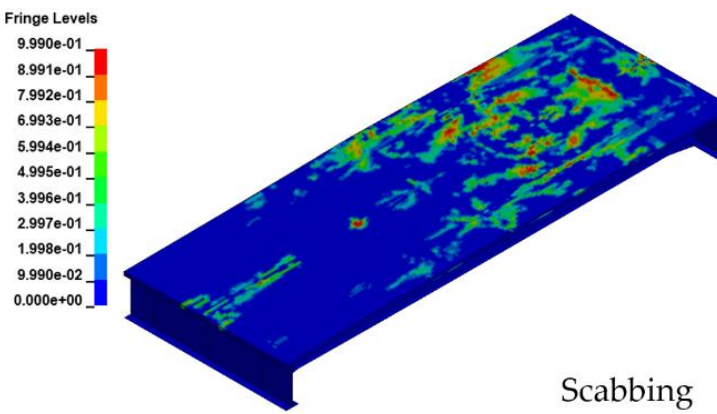

(a)

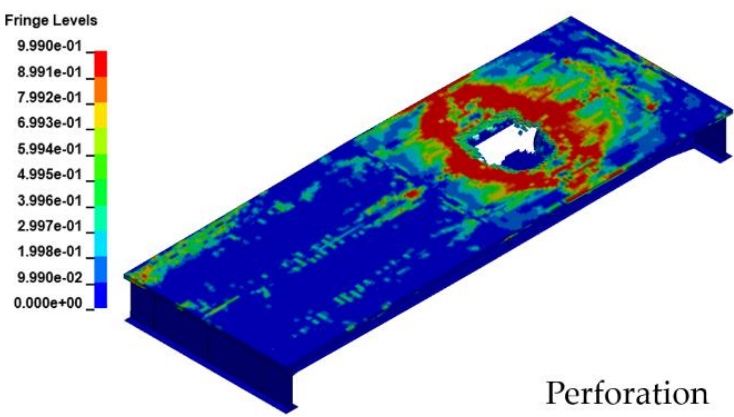

(c)

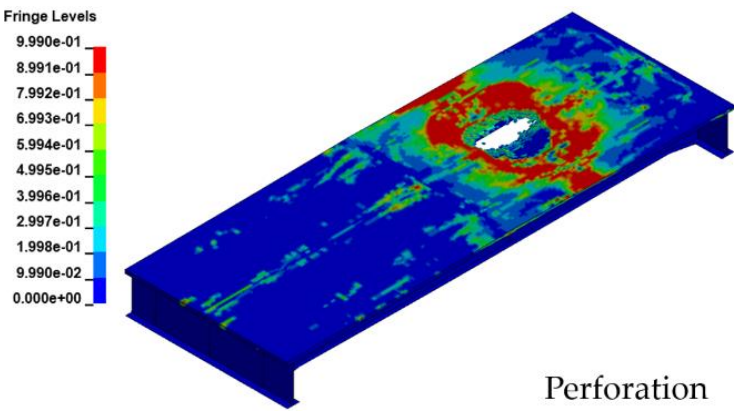

(b)

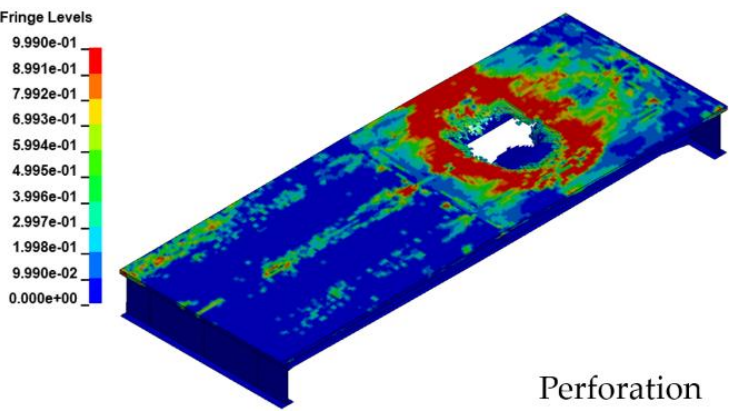

(d)

Figure 11. Damage contours of the deck (above the crossbeam): (a) Scenario A, (b) Scenario B, (c) Scenario C, and (d) Scenario D.

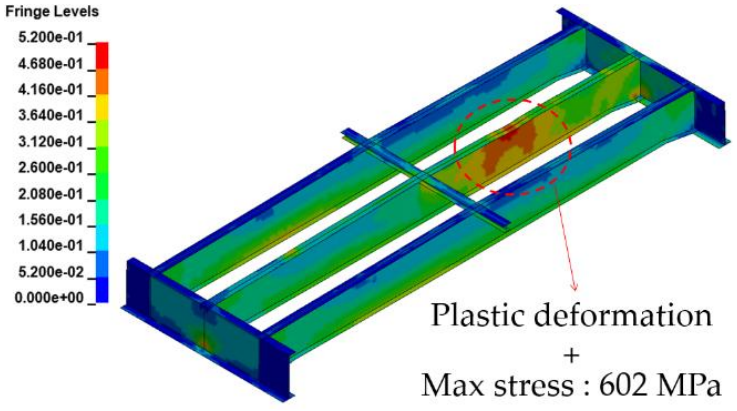

(a)

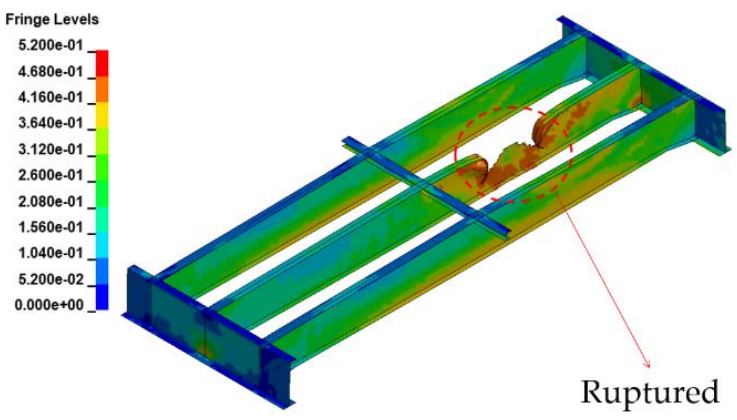

(c)

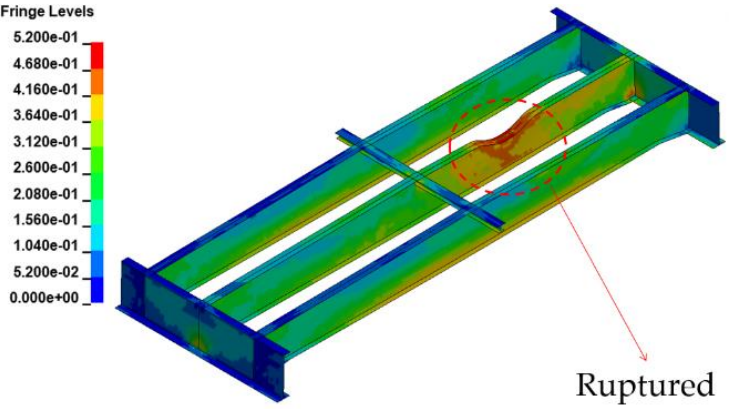

(b)

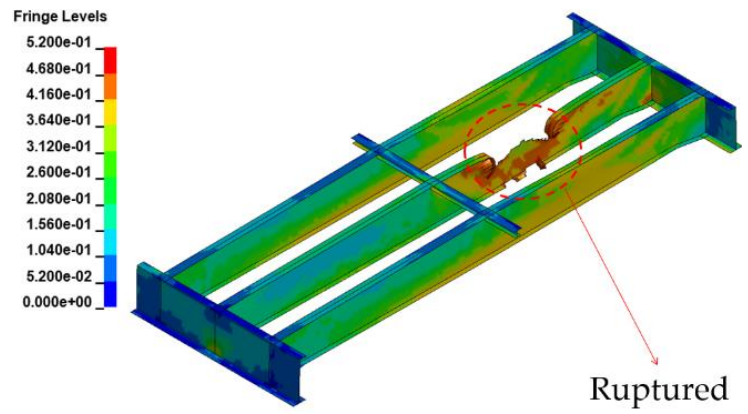

(d)

Figure 12. Effective stress contours of the steel girder (above the crossbeam): (a) Scenario A, (b) Scenario B, (c) Scenario C, and (d) Scenario D (fringe level unit: MPa). 


\subsection{Cable}

Table 8 presents the maximum displacement and maximum effective stress of each scenario when a blast load was applied to each cable selected in this study (see Figure 2). The displacements and effective stresses on the cables increased with the blast load. In scenario D of Cable no. 53, a momentary stress was found to exceed the static tensile strength $\left(f_{p u}\right)$ of the cable $(1765 \mathrm{MPa})$; however, no damage or breakage was observed, owing to the strain rate effect of the material. Furthermore, when the initial stress was excluded, the stresses resulting from the blast load only were found to be approximately 531-1292 MPa for Cable no. 37, 824-1258 MPa for Cable no. 53 and 646-1095 MPa for Cable no. 68 depending on the scenario. Cable no. 37 is observed to have the largest stress variation compared to the initial stress of the design. The reason for this is that Cable no. 37 has a maximum diameter, or maximum blast load reception area. In addition, the maximum displacement and the maximum effective stress occurred on Cable no. 53, which has a minimum cable diameter. These results suggest that the diameter of the cable has a greater influence on the behavior of stay-cables under blast load, or a cable with a small diameter is more vulnerable to blast load. Figures 13 and 14 show the displacement and effective stress contours resulting from the blast load. The fringe range of the displacement contour was set as $0-400 \mathrm{~mm}$, and that of the effective stress contour was set to $0-1765 \mathrm{MPa}$, considering the tensile strength of the cable. The result output time was $0.18 \mathrm{~s}$ and $0.05 \mathrm{~s}$, at which point the maximum displacement and effective stress have occurred.

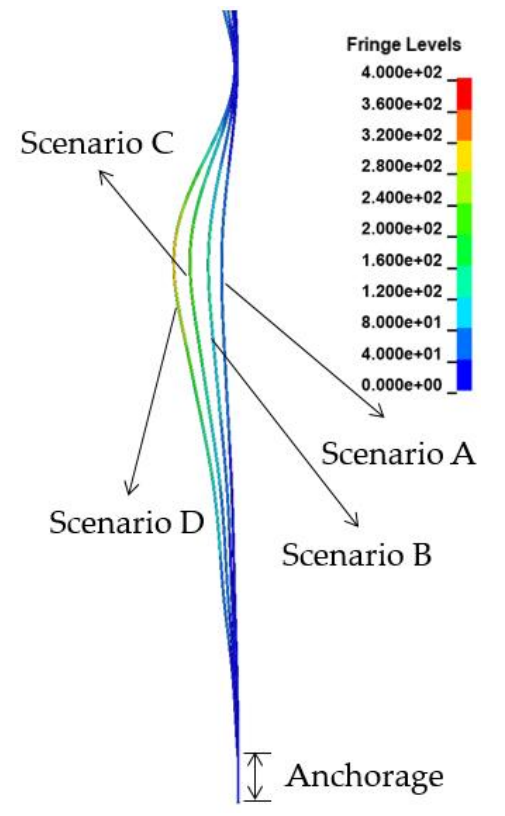

(a)

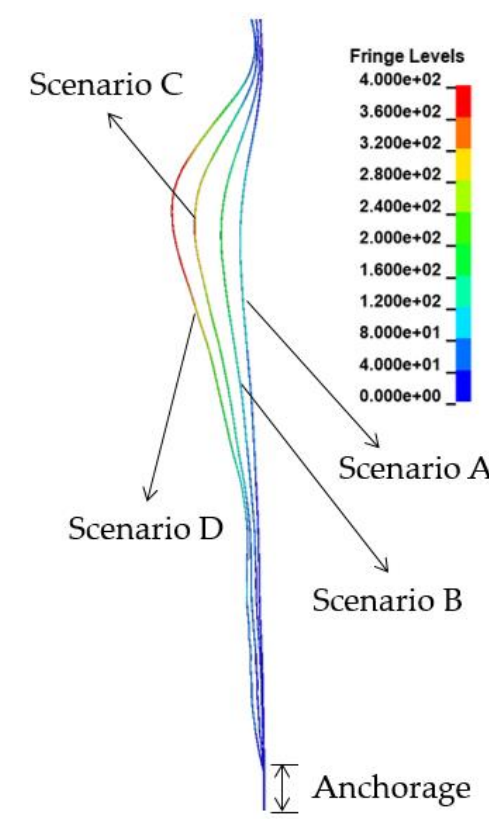

(b)

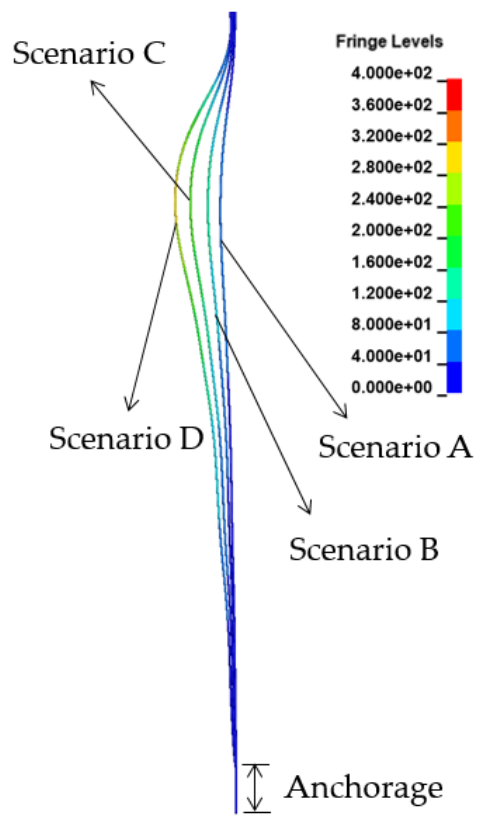

(c)

Figure 13. Displacement contours of cables: (a) Cable no. 37, (b) Cable no. 53, and (c) Cable no. 68 (fringe level unit: $\mathrm{mm}$ ). 


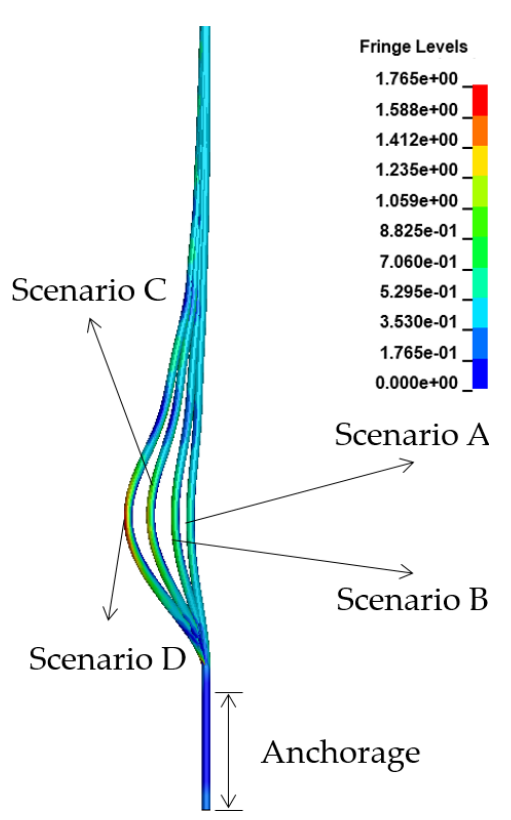

(a)

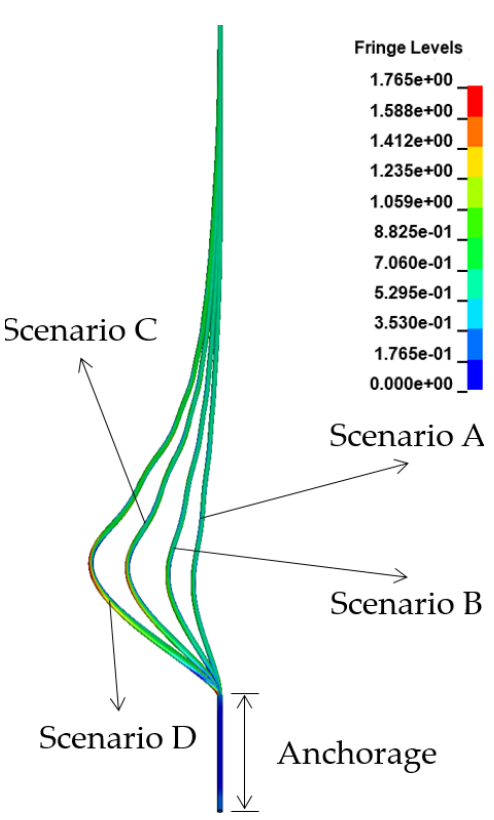

(b)

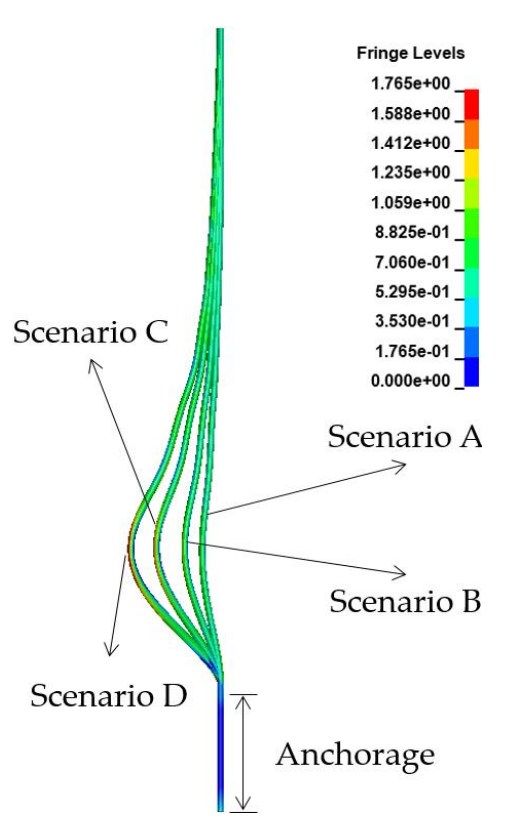

(c)

Figure 14. Effective stress contours of cables: (a) Cable no. 37, (b) Cable no. 53, and (c) Cable no. 68 (fringe level unit: GPa).

Table 8. Summary of blast analysis results for the cables.

\begin{tabular}{cccc}
\hline Blast Scenario & Blast Position & Maximum Displacement & Maximum Stress \\
\hline Scenario A & & $74.65 \mathrm{~mm}$ & $946 \mathrm{MPa}$ \\
Scenario B & Shoulder/ & $133.81 \mathrm{~mm}$ & $1395 \mathrm{MPa}$ \\
Scenario C & Cable no. 37 & $216.94 \mathrm{~mm}$ & $1663 \mathrm{MPa}$ \\
Scenario D & & $289.89 \mathrm{~mm}$ & $1707 \mathrm{MPa}$ \\
\hline Scenario A & & $111.33 \mathrm{~mm}$ & $1380 \mathrm{MPa}$ \\
Scenario B & Shoulder/ & $199.62 \mathrm{~mm}$ & $1656 \mathrm{MPa}$ \\
Scenario C & Cable no. 53 & $321.73 \mathrm{~mm}$ & $1730 \mathrm{MPa}$ \\
Scenario D & & $428.15 \mathrm{~mm}$ & $1814 \mathrm{MPa}$ \\
\hline Scenario A & & $74.94 \mathrm{~mm}$ & $1311 \mathrm{MPa}$ \\
Scenario B & Shoulder/ & $134.96 \mathrm{~mm}$ & $1641 \mathrm{MPa}$ \\
Scenario C & Cable no. 68 & $220.02 \mathrm{~mm}$ & $1703 \mathrm{MPa}$ \\
Scenario D & & $294.46 \mathrm{~mm}$ & $1760 \mathrm{MPa}$ \\
\hline
\end{tabular}

\subsection{Pylon}

Table 9 presents the damage type, rebar stress, and transverse displacement of the pylon under the different blast load scenarios. The damage range of the pylon column was found to increase with the blast load, and the uppermost crossbeam of the pylon was also considerably damaged by the continuous compression. In Scenarios A and B, the concrete element was not eroded, though damage was observed. In Scenario C, partial spalling of the pylon column occurred near the blast load application point and on the underside of the pylon crossbeam. In Scenario D, concrete failure occurred in the portion of the pylon column level with the explosion; at that location the rebar was exposed. The rebar stress was examined based on a yield strength $\left(f_{y}\right)$ of $400 \mathrm{MPa}$, and the rebars in which the stress exceeded the yield strength are marked in red. In Scenarios A and B, very few rebars yielded at the position of the largest blast load. In Scenario C, numerous rebars began to yield and the damage range was increased. The rebars were fractured in Scenario D. It is believed that the rebar in the uppermost crossbeam of the pylon received a relatively small impact from the blast load; however, 
it yielded owing to the continuous compression of the pylon. The maximum transverse displacements of the pylon are as follows: in Scenario A, local displacements of 9.2 and $18.7 \mathrm{~mm}$ occurred at the top of the pylon and at the height of the deck surface, respectively; in Scenarios B and C, local displacements of 19.1 and $59.1 \mathrm{~mm}$ at the pylon top and 32.8 and $78.6 \mathrm{~mm}$ at the height of the deck surface were observed, respectively; and in Scenario D, displacements of 636.6 and $649.7 \mathrm{~mm}$ occurred at the pylon top and the height of the deck surface, respectively, along with a partial fracture of the pylon. Thus, the blast affected the local behavior of the pylon in Scenarios A-C; however, in Scenario D, it affected the overall behavior of the pylon and was even predicted to result in its collapse. Figures 15-17 show the damage contours, axial stress contours, and displacement contours caused by the blast load. The measurement range of the axial stress contours was set to 0-400 MPa considering the yield strength of the rebar, and the measurement range of the displacement contours was set separately, considering the displacement for each scenario. The resulting output time was $1 \mathrm{~s}$, at which point the analysis was terminated.

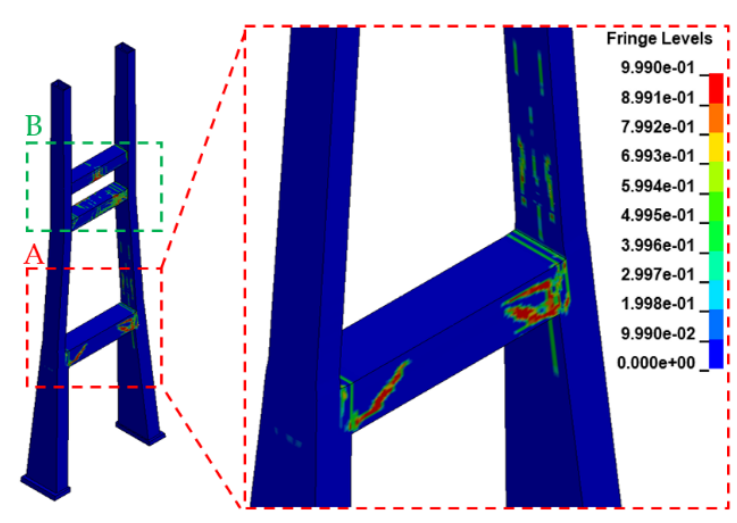

(a)

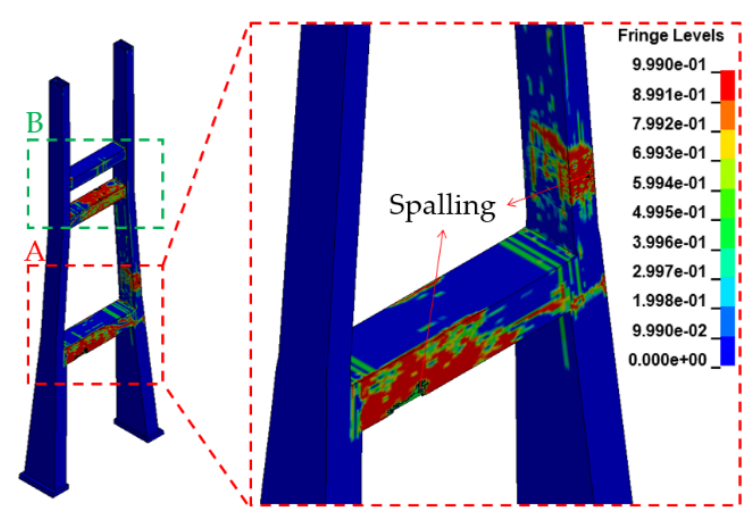

(c)

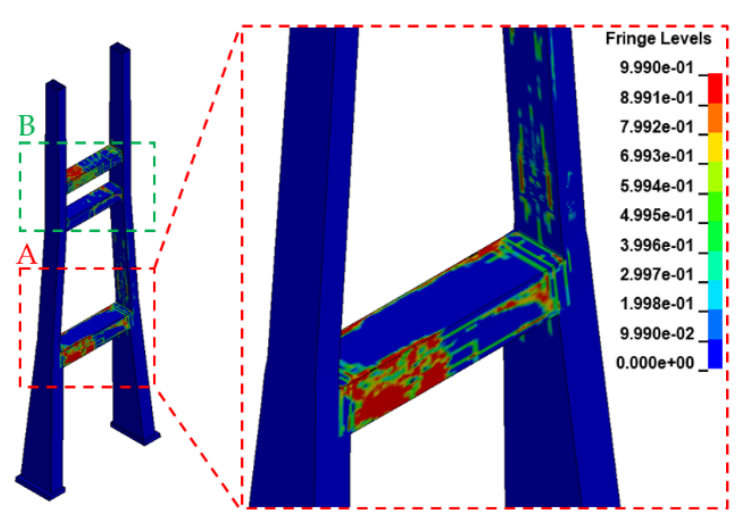

(b)

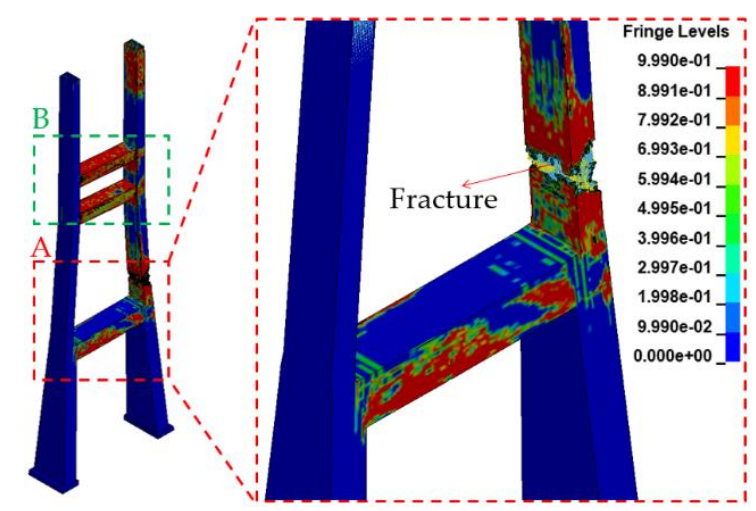

(d)

Figure 15. Damage contours of the pylon: (a) Scenario A, (b) Scenario B, (c) Scenario C, and (d) Scenario D. 


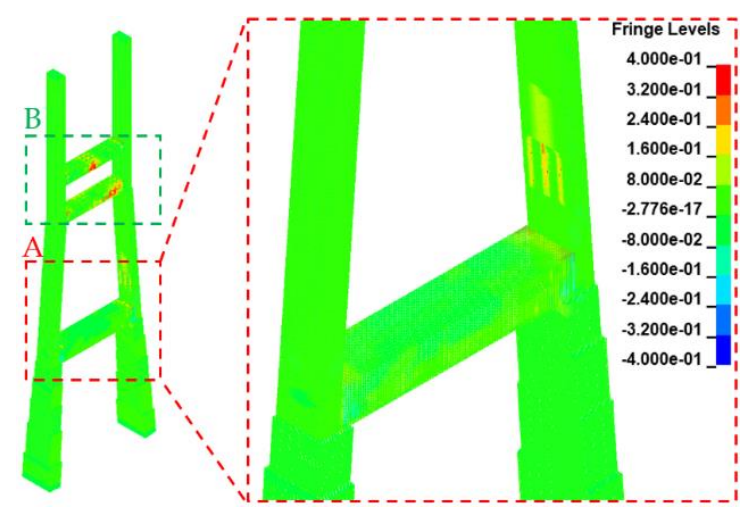

(a)

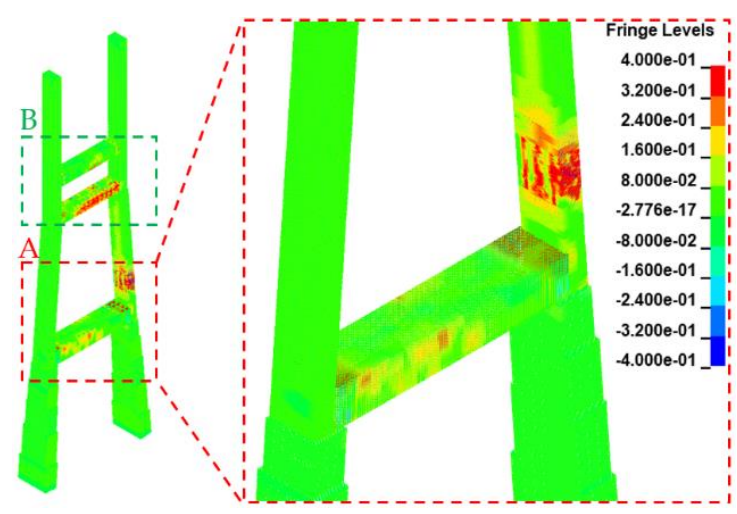

(c)

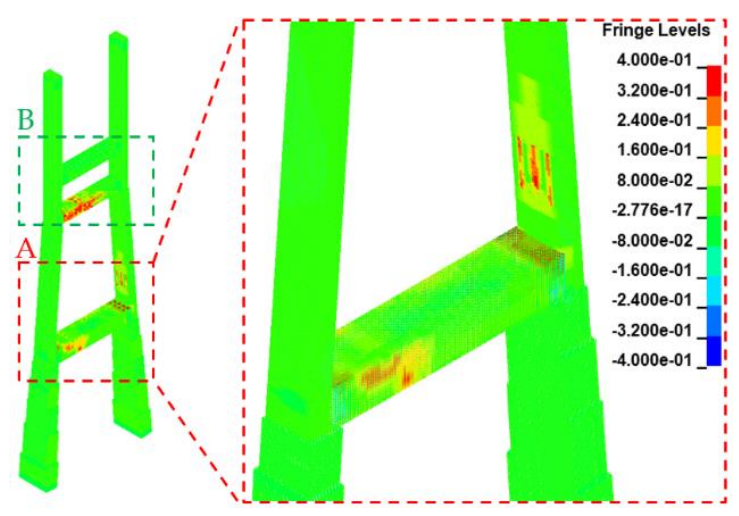

(b)

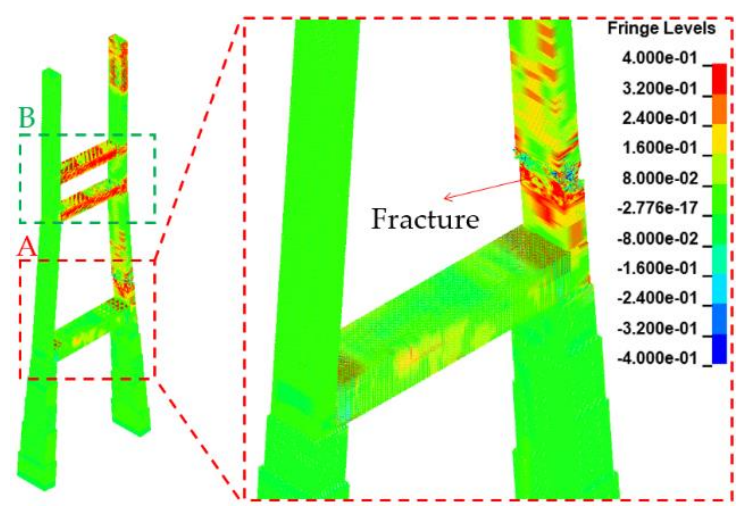

(d)

Figure 16. Axial stress contours of the pylon rebars: (a) Scenario A, (b) Scenario B, (c) Scenario C, and (d) Scenario D (fringe level unit: GPa).

Table 9. Summary of blast analysis results for the pylon.

\begin{tabular}{|c|c|c|c|c|c|c|}
\hline \multirow{3}{*}{$\begin{array}{c}\text { Blast } \\
\text { Scenario }\end{array}$} & \multirow{3}{*}{$\begin{array}{l}\text { Blast } \\
\text { Position }\end{array}$} & \multicolumn{3}{|c|}{ Damage Type } & \multirow{2}{*}{\multicolumn{2}{|c|}{$\begin{array}{c}\text { Maximum Transverse } \\
\text { Displacement }\end{array}$}} \\
\hline & & \multirow{2}{*}{ Concrete } & \multicolumn{2}{|c|}{ Rebar } & & \\
\hline & & & A Zone & B Zone & Upper Part & Road Surface \\
\hline Scenario A & \multirow{4}{*}{ Shoulder } & - & Yield & Yield & $9.2 \mathrm{~mm}(\leftarrow)$ & $18.7 \mathrm{~mm}(\rightarrow)$ \\
\hline Scenario B & & - & Yield & Yield & $19.1 \mathrm{~mm}(\leftarrow)$ & $32.8 \mathrm{~mm}(\rightarrow)$ \\
\hline Scenario C & & Spalling & Yield & Yield & $59.1 \mathrm{~mm}(\leftarrow)$ & $78.6 \mathrm{~mm}(\rightarrow)$ \\
\hline Scenario D & & Fracture & Fracture & Yield & $636.6 \mathrm{~mm}(\rightarrow)$ & $649.7 \mathrm{~mm}(\leftarrow)$ \\
\hline
\end{tabular}




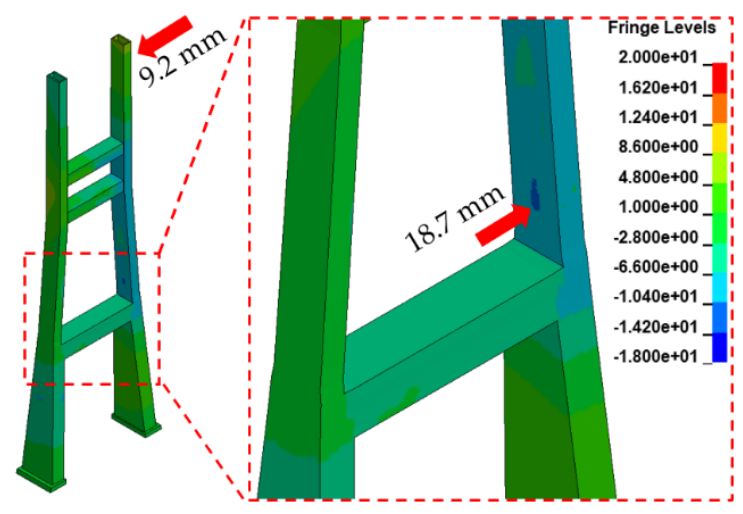

(a)

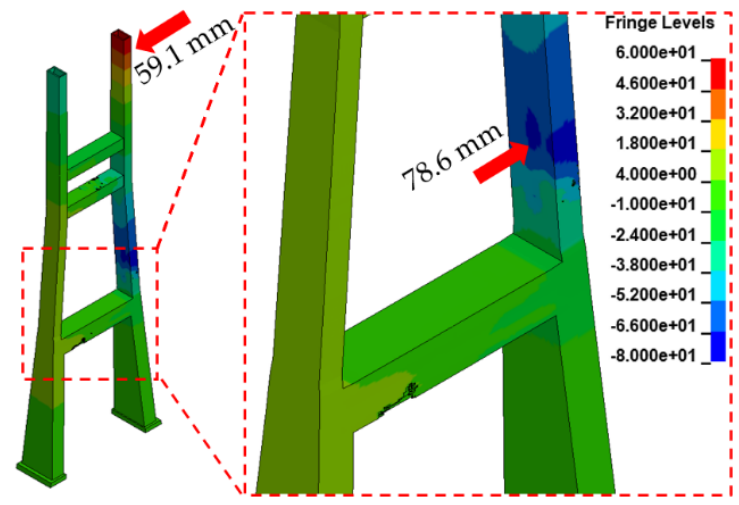

(c)

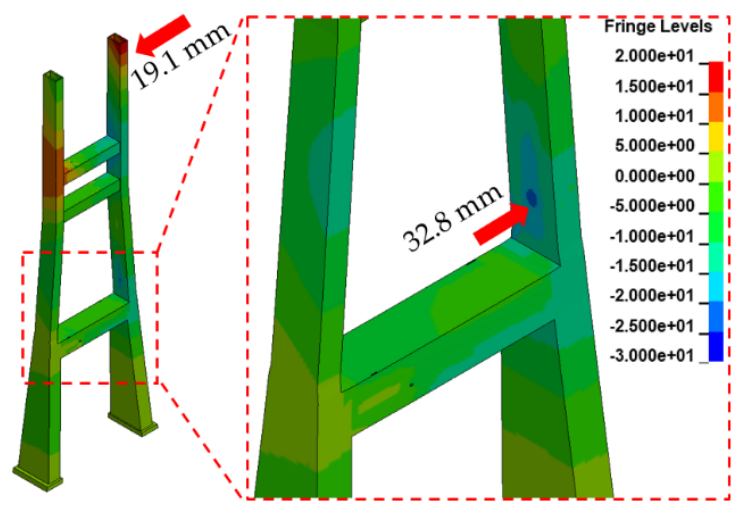

(b)

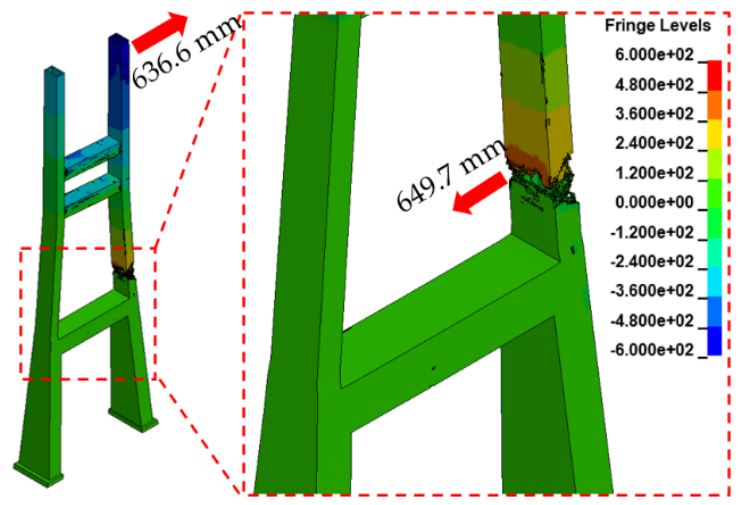

(d)

Figure 17. Displacement contours of the pylon: (a) Scenario A, (b) Scenario B, (c) Scenario C, and (d) Scenario D (fringe level unit: $\mathrm{mm}$ ).

\section{Conclusions}

The performances of key components in a cable-stayed bridge (deck, cable, and pylon) were evaluated via numerical analysis, and all responses for the components and damage type were examined for a range of strategically targeted blast events. The main findings of this study are as follows:

- The study introduced an appropriate blast scenario setting method to facilitate the performance evaluations of the main components of a cable-stayed bridge under a blast load. Furthermore, a method for modeling these components was proposed, which was sensitive to the structural characteristics of such bridges.

- A superstructure blast analysis was conducted in each scenario according to the blast position, and the results were examined. The results showed that the damage range of the components increased with the blast load. The damage types observed included the scabbing and perforation of the slab, as well as the deformation and fracture of the steel girder. Furthermore, the superstructure was more vulnerable to a blast above the crossbeams than between them.

- A blast analysis was conducted in each scenario for cables of different diameters, lengths, and design stresses. The results showed that the maximum displacement and effective stress in each cable increased with the blast load, and no cable fractures occurred in all scenarios. The increase in effective stress (relative to the initial stress of the cable) generated by the blast load was approximately 531-1292 MPa for Cable no. 37 (which had the maximum diameter), 824-1258 MPa for Cable no. 53 (which had the minimum diameter) and 646-1095 MPa for Cable no. 68 (which had the maximum design stress). As such, the maximum stress variation was 
observed on Cable no. 37. However, the maximum displacement and effective stress occurred on Cable no. 53, which had a minimum cable diameter. Therefore, in the case of cables, a blast near the cable with a small diameter tends to have a large impact on the behavior of the cable-stayed bridge.

- For evaluating pylon characteristics, the case wherein a blast occurred on the hard shoulder was examined. The results show that the damage range of the pylon increased with the blast load, and the concrete and rebars were fractured in some scenarios. The damage and rebar yield occurred primarily in the pylon column and the upper cross beams, wherein the applied blast load was largest. The significant damage in the upper crossbeams was considered to be due to the continuous compression of the pylon. Furthermore, the maximum transverse displacement caused by the blast load was examined, and it was found to have an impact on the local behavior of the pylon for Scenarios A-C; however, for Scenario D, it was found to affect the overall behavior of the pylon, with displacements of 636.6 and $649.7 \mathrm{~mm}$ being observed at the top of the pylon and at the deck height in the column, respectively. Therefore, the pylon may be severely damaged under Scenario D.

These results indicate that the blast analysis method introduced in this study will be useful for evaluating the blast load performances of the individual components of cable-stayed bridges. If a performance evaluation of the entire bridge system can be conducted alongside this method, it will become possible to conduct a detailed review of the structural performances of bridges during operation.

Author Contributions: Conceptualization, methodology, writing-review and editing, and supervision, J.L.; methodology, formal analysis, investigation, and writing-original draft preparation, K.C.; conceptualization and supervision, C.C. All authors have read and agreed to the published version of the manuscript.

Funding: This work was supported by a Korea Agency for Infrastructure Technology Advancement (KAIA) grant, funded by the Ministry of Land, Infrastructure, and Transport (Grant No.20SCIP-B119963-05); it was also supported by the Basic Science Research Program through the National Research Foundation of Korea (NRF-2018R1A6A1A07025819).

Conflicts of Interest: The authors declare no conflict of interest.

\section{References}

1. Jenkins, B.M. Protecting Surface Transportation System and Patrons from Terrorist Activities; Mineta Transportation Institute, San José State University: San Jose, CA, USA, 1997.

2. Ray, J.C. Validation of numerical modeling and analysis of steel bridge towers subjected to blast loadings. In Proceedings of the Structures Congress: Structural Engineering and Public Safety, St. Louis, MO, USA, 18-21 May 2006.

3. Fujikura, S.; Bruneau, M.; Lopez-Garcia, D. Experimental Investigation of multihazard resistant bridge piers having concrete-filled steel tube under blast loading. J. Bridge Eng. 2008, 13, 586-594. [CrossRef]

4. Fujikura, S.; Bruneau, M. Experimental Investigation of seismically resistant bridge piers under blast loading. J. Bridge Eng. 2011, 16, 63-71. [CrossRef]

5. Williams, E.B.; Bayrak, O.; Davis, C.; Williams, G.D. Performance of bridge columns subjected to blast loads. I: Experimental program. J. Bridge Eng. 2011, 16, 693-702. [CrossRef]

6. Foglar, M.; Kovar, M. Conclusions from experimental testing of blast resistance of FRC and RC bridge decks. Int. J. Impact Eng. 2013, 59, 18-28. [CrossRef]

7. Hajek, R.; Fladr, J.; Pachman, J.; Stoller, J.; Foglar, M. An experimental evaluation of the blast resistance of heterogeneous concrete-based composite bridge decks. Eng. Struct. 2019, 179, 204-210. [CrossRef]

8. Williams, E.B.; Bayrak, O.; Davis, C.; Williams, G.D. Performance of bridge columns subjected to blast loads. II: Results and recommendations. J. Bridge Eng. 2011, 16, 703-710. [CrossRef]

9. Williams, G.D.; Williams, E.B. Response of reinforced concrete bridge columns subjected to blast loads. J. Struct. Eng. 2011, 137, 903-913. [CrossRef]

10. Winget, D.G.; Marchand, K.A.; Williamson, E.B. Analysis and design of critical bridges subjected to blast loads. J. Struct. Eng. 2005, 131, 1243-1255. [CrossRef]

11. Anwarul Islam, A.K.M.; Yazdani, N. Performance of AASHTO girder bridges under blast loading. Eng. Struct. 2008, 30, 1922-1937. [CrossRef] 
12. Pan, Y.; Chan, B.Y.B.; Cheung, M.M.S. Blast loading effects on an RC slab-on-girder bridge superstructure using the multi-euler domain method. J. Bridge Eng. 2013, 18, 1152-1163. [CrossRef]

13. Andreou, M.; Kotsoglou, A.; Pantazopoulou, S. Modeling blast effects on a reinforced concrete bridge. Adv. Civ. Eng. 2016, 4167329, 1-11.

14. Deng, R.-B.; Jin, X.-L. Numerical simulation of bridge damage under blast loads. WSEAS Trans. Comput. 2009, 8, 1564-1574.

15. Tang, E.K.C.; Hao, H. Numerical simulation of a cable-stayed bridge response to blast loads, part I: Model development and response calculations. Eng. Struct. 2010, 32, 3180-3192. [CrossRef]

16. Hao, H.; Tang, E.K.C. Numerical simulation of a cable-stayed bridge response to blast loads, part II: Damage prediction and FRP strengthening. Eng. Struct. 2010, 32, 3193-3205. [CrossRef]

17. Son, J.; Lee, H.-J. Performance of cable-stayed bridge pylons subjected to blast loading. Eng. Struct. 2011, 33, 1133-1148. [CrossRef]

18. Bojanowski, C.; Balcerzak, M. Response of a large span stay cable bridge to blast loading. In Proceedings of the 13th International LS-DYNA Users Conference, Dearborn, MI, USA, 8-10 June 2014.

19. Hashemi, S.K.; Bradford, M.A.; Valipour, H.R. Dynamic response of cable-stayed bridge under blast load. Eng. Struct. 2016, 127, 719-736. [CrossRef]

20. Hashemi, S.K.; Bradford, M.A.; Valipour, H.R. Dynamic response and performance of cable-stayed bridge under blast load: Effect of pylon geometry. Eng. Struct. 2017, 137, 50-66. [CrossRef]

21. Pan, Y.; Ventura, C.E.; Cheung, M.M.S. Performance of highway bridges subjected to blast loads. Eng. Struct. 2017, 151, 788-801. [CrossRef]

22. Farahmand-Tabar, S.; Barghian, M.; Vahabzadeh, M. Investigation of the progressive collapse in a suspension bridge under the explosive load. Int. J. Steel Struct. 2019, 19, 2039-2050. [CrossRef]

23. Korea Expressway Corporation. Practical applications of Long-termly Measured Data on Cable-supported Bridges; Korea Expressway Corporation: Gimcheon, Korea, 2007.

24. LSTC (Livermore Software Technology Corporation). LS-DYNA Keyword User's Manual; Livermore Software Technology Corporation: Livermore, CA, USA, 2018.

25. Murray, Y.D. User Manual for LS-DYNA Concrete Material Model 159; Report No, FHWA-HRT-05-062; Federal Highway Administration: Olympia, WA, USA, 2007.

26. Murray, Y.D. User Manual for LS-DYNA Concrete Material Model 159; Report No, FHWA-HRT-05-063; Federal Highway Administration: Olympia, WA, USA, 2007.

27. Choung, J.M.; Shim, C.S.; Kim, K.S. Plasticity and fracture behavior of marine structural steel, part I: Theoretical background of strain hardening and rate hardening. J. Ocean. Eng. Technol. 2011, 25, 134-144. [CrossRef]

28. Gimsing, N.J.; Georgakis, C.T. Cable Supported Bridges: Concept and Design, 3rd ed.; John Wiley \& Sons: Hoboken, NY, USA, 2012.

29. Krauthammer, T. Modern Protective Structures; CRC Press: Boca Raton, FL, USA, 2008.

30. Orbovic, N.; Grimes, J.; El-Domiaty, K.; Florek, J. ASME blast test on pre-stressed concrete slabs. In Proceedings of the 24th Conference on Structural Mechanics in Reactor Technology, Busan, Korea, 20-25 August 2017; BEXCO: Busan, Korea, 2017.

Publisher's Note: MDPI stays neutral with regard to jurisdictional claims in published maps and institutional affiliations.

(C) 2020 by the authors. Licensee MDPI, Basel, Switzerland. This article is an open access article distributed under the terms and conditions of the Creative Commons Attribution (CC BY) license (http://creativecommons.org/licenses/by/4.0/). 